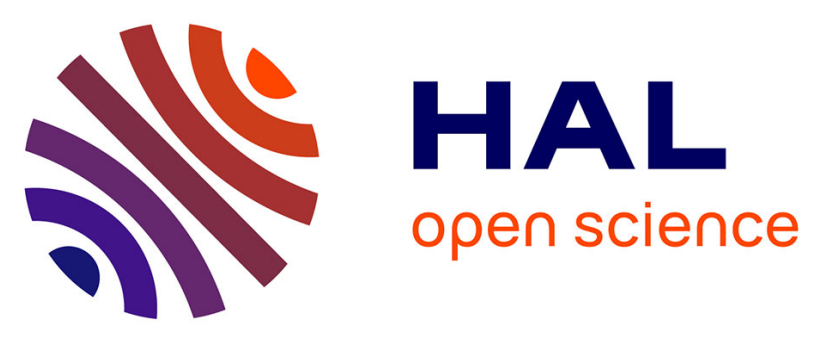

\title{
Polypharmacy, length of hospital stay, and in-hospital mortality among elderly patients in internal medicine wards. The REPOSI study
}

Alessandro Nobili, Giuseppe Licata, Francesco Salerno, Luca Pasina, Mauro Tettamanti, Carlotta Franchi, Luigi Vittorio, Alessandra Marengoni, Salvatore Corrao, Alfonso Iorio, et al.

\section{To cite this version:}

Alessandro Nobili, Giuseppe Licata, Francesco Salerno, Luca Pasina, Mauro Tettamanti, et al.. Polypharmacy, length of hospital stay, and in-hospital mortality among elderly patients in internal medicine wards. The REPOSI study. European Journal of Clinical Pharmacology, 2011, 67 (5), pp.507-519. 10.1007/s00228-010-0977-0 . hal-00658700

\section{HAL Id: hal-00658700 https://hal.science/hal-00658700}

Submitted on 11 Jan 2012

HAL is a multi-disciplinary open access archive for the deposit and dissemination of scientific research documents, whether they are published or not. The documents may come from teaching and research institutions in France or abroad, or from public or private research centers.
L'archive ouverte pluridisciplinaire HAL, est destinée au dépôt et à la diffusion de documents scientifiques de niveau recherche, publiés ou non, émanant des établissements d'enseignement et de recherche français ou étrangers, des laboratoires publics ou privés. 


\section{Polypharmacy, lenghth of hospital stay, and in-hospital mortality among elderly patients in hospital internal medicine wards. The REPOSI Study.}

Alessandro Nobili ${ }^{1}$, Giuseppe Licata $^{2}$, Francesco Salerno ${ }^{3}$, Luca Pasina ${ }^{1}$, Mauro Tettamanti ${ }^{1}$, Carlotta Franchi ${ }^{1}$, Luigi De Vittorio ${ }^{1}$, Alessandra Marengoni ${ }^{4}$, Salvatore Corrao ${ }^{2}$, Alfonso Iorio ${ }^{5}$, Maura Marcucci ${ }^{5}$, Pier Mannuccio Mannucci ${ }^{6}$ on behalf of SIMI* Investigators.

1. "Mario Negri”' Institute for Pharmacological Research, Milano, Italy.

2. Dipartimento Biomedico di Medicina Interna e Specialistica, University of Palermo, Italy.

3. Medicina Interna, IRCCS Policlinico San Donato, University of Milano, Italy.

4. Department of Medical and Surgery Sciences, University of Brescia. Geriatric Ward, Spedali Civili, Brescia, Italy.

5. Department of Internal Medicine, University of Perugia, Italy.

6. Scientific Direction, IRCCS Cà Granda Foundation Maggiore Policlinico Hospital, Milan, Italy.

* SIMI, Italian Society of Internal Medicine. The participating hospitals and coauthors are listed in the Acknowledgements.

\section{Corresponding author:}

Alessandro Nobili

Laboratory for Quality Assessment of Geriatric Therapies and Services

Mario Negri Institute for Pharmacological Research

via Giuseppe La Masa, 19

20156 Milan, Italy

Phone: +3902 39014512

Fax: +3902 39001916

E-mail:nobili@marionegri.it 


\begin{abstract}
Purposes: To evaluate the prevalence and factors associated with polypharmacy, and to investigate the role of polypharmacy as a predictor of length of hospital stay and in-hospital mortality. Methods: Thirty-eight internal medicine wards in Italy participated in the Registro Politerapie

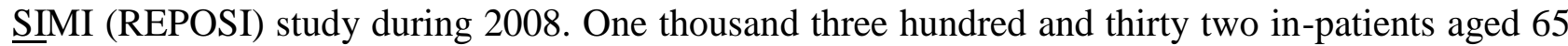
years or older were enrolled. Polypharmacy was defined as the concomitant use of five or more medications. Linear regression analyses were used to evaluate predictors of length of hospital stay, and logistic regression models for predictors of in-hospital mortality. Age, sex, Charlson's index, polypharmacy, and number of in-hospital clinical adverse events (AEs) were used as possible confounders.
\end{abstract}

Results: The prevalence of polypharmacy was $51.9 \%$ at hospital admission and $67.0 \%$ at discharge. Age, number of drugs at admission, hypertension, ischemic heart disease, heart failure, and chronic obstructive pulmonary disease were independently associated with polypharmacy at discharge. In multivariate analysis, the occurrence of at least one $\mathrm{AE}$ while in hospital was the only predictor of prolonged hospitalization (each new AE prolonged hospital stay by 3.57 days, $\mathrm{p}<0.0001)$. Age (OR 1.04; 95\%CI: 1.01-1.08; $\mathrm{p}=0.02)$, comorbidities (OR 1.18; 95\%CI: 1.12-1.24; $\mathrm{p}<0.0001)$, and AEs (OR 6.80; 95\%CI: 3.58-12.9; $\mathrm{p}<0.0001)$ were significantly associated with in-hospital mortality.

Conclusions: Although most elderly in-patients receive polypharmacy, in this study it was not associated with any hospital outcome. However, AEs were strongly correlated with a longer hospital stay and higher mortality risk.

Key words: elderly, polypharmacy, hospital stay, in-hospital mortality 


\section{Introduction}

Polypharmacy is a problem for rational drug prescribing in elderly patients (1-4), who are the greatest consumers of medicines, often taking from two to five drugs on a regular basis. A survey of community-dwelling elderly showed that more than $90 \%$ of those aged 65 years or more used at least one drug weekly and more than $40 \%$ took five or more (5). Among hospitalized elderly, the prevalence of polypharmacy ranged from $20 \%$ to $60 \%$, reflecting different criteria used to select patients and collect medication data (6-8). Although polypharmacy has no generally accepted definition, most often it is defined by cut-offs, in terms of the number of medications taken, ranging from two to ten (9-12). However, regardless of the definition, its prevalence has been reported to rise with age, and is associated with an increased risk of inappropriate drug prescription, under-use of effective treatment, medication errors, poor adherence to pharmacological therapies, drug/drug and drug/disease interactions, and adverse effects (3,13-18).

The incidence of adverse drug reactions (ADRs) rises exponentially rather than linearly with the number of drugs taken, and advanced age and polypharmacy are associated with a substantial increase in the risk of ADRs $(4,10,15,19-21)$.

Polypharmacy is often a consequence of multiple chronic conditions, which lead physicians to prescribe more than one drug, increasing the risk of disability, hospitalization, and mortality (2227). Although the available guidelines have improved and rationalized drug prescription in many disease-oriented fields, they are still weak for elderly people with multiple chronic conditions exposed to polypharmacy (28-29). One chronic condition can potentially worsen another, and drugs can interact negatively with others, increasing the risk of ADRs and reducing the expected benefit. Older patients and patients with multiple chronic disorders are almost always excluded from trials to verify the effectiveness of drugs, because of the fear they may be unable to complete the studies 
because of poor compliance, frequent side effects or death. Therefore many drugs are subsequently used in these patients even though their benefit-risk profile in not known (27-28).

Many risk factors for polypharmacy have been identified, including demographic aspects such as age, white race, education, sex, poor health, number of chronic diseases, living arrangements, and the number and characteristics health providers $(1-2,14-16)$. Elderly patients with multiple chronic conditions are common in general medicine specialties such as internal and geriatric medicine. They are usually frail, are highly sensitive to pharmacotherapy because of changes in their pharmacokinetic and pharmacodynamic parameters, and are often admitted with acute diseases, which may increase their susceptibility to polypharmacy $(10,21)$.

Hospitalization is a major risk for older persons, particularly the very old. In many cases hospitalization is associated with an irreversible decline in functional status, cognitive performance, and quality of life $(14,20,24,30)$. Although polypharmacy and the risk of inappropriate use of medications in community-living and institutionalized elderly patients have been amply described, few studies have analyzed the prevalence, the predictors and the in-hospital outcomes of polypharmacy in elderly.

The aims of this study were to evaluate in a sample of hospitalized elderly people the prevalence of polypharmacy (defined as five or more drugs) at admission and at discharge from internal and geriatric medicine wards, to assess the prevalence of the most frequently prescribed medications, to analyze the predictors of polypharmacy at hospital discharge, and to investigate the role of polypharmacy as a predictor of longer hospital stay and raising in-hospital mortality.

\section{Methods}

This prospective cohort study ran from January 2008 to December 2008 in 38 hospitals in different

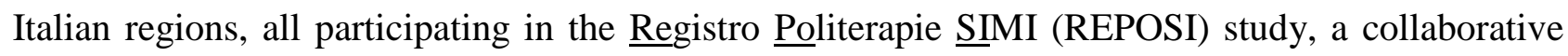


effort between the Italian Society of Internal Medicine (SIMI) and the Mario Negri Institute for Pharmacological Research. The REPOSI study was designed with the purpose of setting up a network of internal medicine wards to investigate the prevalence and correlates of polymorbidity and polypharmacy in hospitalized elderly patients. Participation was voluntary, but in the choice of participating centers, we were careful to ensure they were representative in terms of country-wide distribution and size, and had unselected admissions from their own territory or the emergency room.

The REPOSI study was specifically designed to describe the prevalence of multiple concurrentdiseases and treatments in hospitalized elderly patients, to correlate the patient's clinical characteristics with the type and number of diseases and treatments, and to evaluate the main clinical outcomes at discharge.

\section{Study population}

Patients were eligible for REPOSI if: 1) they were admitted to one of the 38 participating internal medicine wards during the four index weeks chosen for recruitment (one in February, one in June, one in September, and one in December 2008); 2) their age was 65 years or older; 3) they gave informed consent. Each ward had to enrol at least the first ten consecutive eligible patients during each index week.

During each index week, all wards had to complete the register of all patients admitted to the ward, and indicate those who were consecutively enrolled in the study. For patients who were excluded, the reason had to be given. On the basis of these data, during the four weeks, the recruitment rate for each ward was nearly $40 \%$ of patients admitted. Sixty eight percent of them were excluded because of age under 65 years. Other reasons for exclusion were refusal to participate or to sign informed consent $(23 \%)$, seriousness of patient's clinical condition or admission in terminal state 
(6\%), and other reasons (3\%). No difference for age and sex (the only available data) emerged for these patients in comparison to the enrolled sample.

Out of 1411 patients enrolled, 79 (5.6\%) were excluded because of missing or incomplete data (25 had missing data on hospital outcome, and 54 on most socio-demographic and clinical characteristics due to errors or omissions in data input and recording), and 1332 fulfilled the requirements for the present analysis. The 54 patients excluded because of missing data showed no significant differences in outcomes in comparison to the cohort analyzed.

\section{Data collection}

All data obtained from the patient's medical records entered in a standardized web-based “essential" Case Report Form (CRF) by the attending physicians. The following data were recorded for each patient: basic socio-demographic details, clinical parameters, diagnoses and treatments at hospital admission and discharge, clinical events in hospital, and outcome. Before starting the enrolment, all investigators received instructions on how to standardize the procedure for patients' inclusion, and how to enter and code the data in the electronic CRF. All the data were collected and checked by a central monitor institution (the Mario Negri Institute for Pharmacological Research, Milan).

Data was colleced in full compliance with Italian law on personal data protection. However, under the applicable legal principles on patient registries, the study did not require the approval of an ethical committee.

\section{Diagnoses and comorbidities}

At admission the main reason for hospital admission and any comorbidities were recorded. At discharge, all diagnoses listed in the medical record were recorded. These were confirmed by clinical examination, anamnesis, laboratory and instrumental data collected by the attending 
physicians, and were encoded according to "The International Classification of Diseases, 9th Revision, Clinical Modification" (ICD-9-CM), Sixth Edition (World Health Organization, 1987) (31). Chronic diseases identified by Veehof et al. (12) analyzed as potential predictors of polypharmacy were: hypertension, ischemic heart disease, atrial fibrillation, heart failure, diabetes mellitus, chronic obstructive pulmonary disease or bronchial asthma, osteoporosis or osteoarthritis, gastrointestinal disease (peptic or duodenal ulcer, non-specific bowel inflammation), and psychiatric disorders (dementia, depression). Depression was eventually excluded because there were only four patients.

Comorbidity was evaluated by the Charlson's comorbidity index (32), a method used in longitudinal studies for classifying comorbid conditions that might affect the risk of mortality. This weighted index takes into account the number and seriousness of comorbid diseases. Specific diseases are graded in three levels of severity: low (Charlson's score 2 or less), moderate (Charlson's score 3-4), and severe (Charlson's score 5 or more) according to the level of individual organ function and prognostic importance.

\section{Drugs and polypharmacy}

All drugs taken at hospital admission and all medications recommended at discharge were recorded and encoded according to the Anatomical Therapeutic Chemical classification system (ATC) (WHO 1990) (33). The drug classes were determined in relation to the ATC 3rd level (pharmacological subgroup) classification. The numbers of drugs taken at admission and discharge were compared for each patient.

Although there is still no consensus or commonly used cut-off for polypharmacy, since previous studies have mostly used four or five drugs as cut-off points, and most drugs prescribed to elderly patients are for chronic therapies, we defined polypharmacy as the exposure of a patient to five or 
more different medications $(2-4,9)$. The prevalence of polypharmacy was analyzed in five-year age brackets: $65-69,70-74,75-9,80-84 ; 85-89, \geq 90$ years).

Polypharmacy was evaluated at hospital admission (on the whole sample of 1332 patients) and at discharge (on the 1155 sent home). Data on drug prescription were not available for 111 patients who were not discharged to go home and 66 who died in hospital. However, no statistically significant difference was observed at admission between the socio-demographic and clinical characteristics of 111,66 , and 1155 patients.

\section{Predictors, clinical events and adverse outcome}

Patients' characteristics, diagnoses, comorbidity (Charlson's index), and AEs were considered potential predictors of polypharmacy. AEs were defined as any change in the individual's health, with specific symptoms and signs of recent onset, occurring after hospital admission (34-35). Length of hospital stay, rate of AEs and in-hospital mortality were used as outcome measures when evaluating the effect of polypharmacy,.

Of the 111 patients who were not discharged to go home, and were excluded from the analysis, 61 were transferred to other hospital wards because of acute medical or surgical disease during hospitalization, 44 were transferred to rehabilitation units or long-term facilities, and 6 were terminally ill at admission and were transferred to end-of-life care units.

\section{Statistical analysis}

Categorical variables were expressed as frequency and percentages, and continuous variables as means $( \pm \mathrm{SD})$. The differences in distribution of categorical variables between patients with and without polypharmacy were computed using the chi-squared test, while for continuous variables the t-test was used. 
Determinants of polytreatment at discharge were studied in 551 patients without polypharmacy at admission. We applied logistic regression models to identify the patient-related characteristics associated with polypharmacy. Each model was adjusted for sex, age, number of drugs at admission, and occurrence of at least an $\mathrm{AE}$ in hospital. Diagnoses were separately tested (hypertension, ischemic heart diseases, heart failure, atrial fibrillation, diabetes mellitus, COPD, dementia, cerebrovascular diseases, liver diseases, gastrointestinal disorders, oseoporosis/osteoarthritis, chronic renal failure, anemia, and malignancy). For each variable we calculated the odds ratio (OR) and $95 \%$ confidence interval $(95 \% \mathrm{CI})$.

Outcome measures (predictors of length of hospital stay and in-hospital mortality) were analysed using respectively linear and logistic regression analysis. Regression coefficients, odds ratio and their $95 \%$ confidence interval $(95 \% \mathrm{CI})$ were calculated both at univariate analysis and after adjustment for sex, age, comorbidities at admission (Charlson index score), number of drugs at admission (five or more) and occurrence of at least an AE in hospital. In all multivariate models, standard errors were corrected to allow for the non-independence of patients within the same ward. All statistical calculations were done with the software JMP v 8.0.2 (SAS Institute Inc., Cary, NC, USA) and STATA v11.1 (Stata Corp LP, College Station, Texas, USA).

\section{Results}

Of the 1332 patients enrolled $772(54.2 \%)$ were women, the average age was 79.4 years $\left(\mathrm{SD}_{ \pm} 7.5\right)$, and $616(46 \%)$ were aged 80 years or more. At admission, almost 90\% of patients came from home, where $42 \%$ lived with their spouse, $24 \%$ alone, $19 \%$ with sons, and the remainder lived in a nursing home. The mean number of diagnoses was $5.2(\mathrm{SD} \pm 2.3)$. The Charlson's comorbidity index mean score was $0.5\left(\mathrm{SD}_{ \pm} 0.8\right)$, and $545(40 \%)$ patients had a Charlson index rated as moderate or severe. 
The most frequent diagnoses at hospital admission were hypertension (57.8\%), diabetes mellitus (24.0\%), coronary heart disease (CHD, 23.0\%), atrial fibrillation (AF, 20.6\%), COPD (20.0\%) and CVD (19.5\%).

\section{Prevalence of polypharmacy}

At admission, the patients had an average of $5.2(\mathrm{SD} \pm 2.3)$ diagnoses, were in treatment with an average of $4.9(\mathrm{SD} \pm 2.9)$ drugs, and $51.9 \%$ were taking five or more different drugs (polypharmacy). Figure 1 shows the prevalence of polypharmacy at admission in relation to age. The prevalence rate was highest at ages 70-74 and 80-84 years, with nearly $60 \%$ of patients in polypharmacy. At discharge, the prevalence of patients in polypharmacy increased from $51.9 \%$ to $67.0 \%(+15.1 \%)$, patients were discharged with an average of $6.0(\mathrm{SD} \pm 2.9)$ drugs per person, and an average of $5.9(\mathrm{SD}+2.5)$ diagnoses.

Among the 1155 patients discharged, 341 (29.5\%) had no polypharmacy at either admission and or discharge, $210(18.2 \%)$ shifted to polypharmacy at discharge, $40(3.5 \%)$ were on polypharmacy at admission but not at discharge, and $564(48.8 \%)$ were on polypharmacy at both admission and discharge. Figure 2 compares the distributions of patient in relation to the number of drugs at admission and at discharge, showing a clear increase of patients receiving five or more different medications at discharge.

Table 1 lists the ten most frequently prescribed drug classes at admission and discharge. Except for blood glucose lowering drugs (A10B) the prevalence of treated patients was higher at discharge.

\section{Predictors of polypharmacy}

Table 2 shows the results of univariate analysis of the predictors of polypharmacy in relation to sociodemographic and clinical characteristics, for the 1332 patients at admission and the 1155 discharged; in both samples, age 85 years or more, education, number of diagnoses, Charlson's 
comorbidity index score, number of drugs, number of AEs during hospital stay, diagnosis of hypertension, ischemic heart disease, atrial fibrillation, heart failure, diabetes mellitus, COPD, chronic renal failure, and osteoporosis/osteoarthritis were associated with the use of polypharmacy. At admission, a diagnosis of gastrointestinal disorders was also positively related to polypharmacy. Table 3 analyses the 551 patients without polypharmacy at admission, comparing the sociodemographic and clinical characteristics of the 341 who received less that five drugs at discharge, with the 210 discharged with polypharmacy. At univariate analysis, number of diagnoses, at least one $\mathrm{AE}$, lenght of hospital stay and diagnosis of hypertension, ischemic heart disease, atrial fibrillation, heart failure, COPD, osteoporosis/osteoarthritis, or chronic renal failure were predictors of polypharmacy at discharge.

At multivariate analysis, in the full sample of 1155 patients for whom prescription data were available both at admission and discharge, age, number of drugs at admission, hypertension, ischemic heart disease, heart failure, and COPD were the most important predictors of polypharmacy (Table 4).

In a post-hoc analysis of the same 1155 patients, the predictors of changes in the numbers of drug at admission and at discharge were evaluated. For 148 patients $(13.0 \%)$ the number of drugs at discharge were fewer than at admission (delta $<0)$, while for $295(25.4 \%)$ there was no difference $($ delta $=0)$, and for $712(61.6 \%)$ there was an increase (delta $>0)$. Each disease was separately tested in multivariate analyses, to assess whether it was responsible for the change in the number of drugs at discharge. Hypertension raised the number of drugs at discharge by a mean of 0.33 (95\%CI: 0.09-0.56; $\mathrm{p}=0.008$ ) independently of sex, age, number of drugs at admission, the ward, and the occurrence of at least one AE in hospital. Likewise, ischemic heart disease, heart failure, and COPD increased the number of drugs at discharge by a mean of 0.28 (95\%CI: $0.04-0.53 ; \mathrm{p}=0.02), 0.61$ 
(95\%CI: 0.22-1.00; $\mathrm{p}=0.003$ ), and 0.61 (95\%CI: 0.28-0.95; $\mathrm{p}=0.001$ ). Dementia reduced the number of drugs at discharge by a mean of 0.76 (95\%CI: $0.30-1.22 ; \mathrm{p}=0.0002$ ).

\section{Length of hospital stay and in-hospital mortality}

In the whole sample of 1332 elderly patients, $1155(86.7 \%)$ were discharged to go home, 111 $(8.3 \%)$ were transferred to another ward, and $66(5.0 \%)$ died in hospital. The average hospital stays were respectively $13.1(\mathrm{SD} \pm 11.6), 13.1(\mathrm{SD} \pm 11.3)$, and $10.7(\mathrm{SD} \underline{+8.0})$ days.

Table 5 shows the outcomes at discharge in relation to polypharmacy at admission, and the univariate and multivariate analyses of predictors of length of hospital stay and in-hospital mortality. Both analyses found that at least one AE while in hospital was positively related to the time in hospital, prolonging it by 3.57 days (95\%CI 2.32-4.83; $\mathrm{p}<0.0001)$.

Predictors of in-hospital mortality were age $(\mathrm{OR}=1.04 ; 95 \% \mathrm{CI}$ : $1.01-1.09 ; \mathrm{p}=0.02)$, comorbidity (Charlson's index) $(\mathrm{OR}=1.18 ; 95 \% \mathrm{CI}$ : 1.12-1.24; $\mathrm{p}<0.0001)$. An AE during the hospital stay raised the risk of in-hospital mortality of nearly seven-fold, independently of sex, age, comorbidity and polypharmacy $(\mathrm{OR}=6.80 ; 95 \% \mathrm{CI}: 3.58-12.9 ; \mathrm{p}<0.0001)$. Polypharmacy was not a predictor for either length of hospital stay or in-hospital mortality. Adding the ward to the covariates of logistic regression analysis had no effect on the results.

\section{Sensitivity analysis}

As the chosen cut-off of five or more drugs to define polypharmacy is not unanimously accepted, and in any case to estimate the sensitivity of the results to this cut-off, we re-run the multivariate analysis for four and six or more drugs.

The estimates for the predictors of length of hospital stay and mortality were almost identical to those reported in Table 5, with statistical significance confirmed for the same variables. 
Among different diseases, while hypertension and heart failure were still statistically significant, others were not always present, probably because of random fluctuations or complex interactions between the single variables in the full model.

\section{Discussion}

This study shows how common is polypharmacy in elderly patients admitted to an internal medicine or geriatric ward. More than $50 \%$ of patients aged 65 years or more in a network of 38 Italian internal medicine hospital wards, voluntarily participating in the REPOSI Project, were taking five or more different drugs (polypharmacy), mostly as chronic therapies. Polypharmacy was more common in people between 70 and 84 years, and was related to comorbidities. The decline in polypharmacy after 85 years of age might be due to poor drug tolerance with age or with doctors' fears of serious side-effects being more common in very old patients, as a reduction of morbidity with age is not likely.

Hospitalization did not lead to any reduction in the number of drugs. Only $13 \%$ of patients had fewer drugs prescribed at discharge than at admission, and more than $60 \%$ had an increase. Moreover, among patients admitted with polypharmacy, only 3.5\% were discharged with fewer than five different medicines.

This finding suggests that most of the disorders affecting elderly people admitted to hospital are chronic and need stable therapy. The increase in the number of prescriptions at discharge suggests that hospitalization leads to new diagnoses which require further drugs or that old therapies need to be replaced by new, more complex therapies. The increases involved all classes of drugs, thus excluding that the additional drugs are needed because of inadequate treatment at home.

\section{Prevalence of polypharmacy}


Only a few studies have analyzed the prevalence of polypharmacy in a general hospital setting. They used different thresholds for polypharmacy and the prevalence at admission ranged from $20 \%$ to $60 \%$ (6-7), and was higher at hospital discharge. In the Wawruch study (7), which analyzed 600 patients aged 65 years or more in an internal medicine ward, the prevalence of polypharmacy (six or more drugs) at admission was $60 \%$, rising to $62 \%$ at discharge. Another study (8) found that among 543 patients aged 75 or older admitted to selected internal wards, $58 \%$ were taking more than six different medications. Finally, 57\% of 2465 elderly patients admitted to geriatric and internal medicine wards were using more drugs at discharge than in the month before admission (6).

Our analysis showed that nearly $40 \%$ of 1155 elderly patients discharged to home, who at admission were taking less than five different medicines, had shifted to polypharmacy at discharge. On average they were taking five drugs at admission and six at discharge, thus fewer than in other studies, which reported an average of six and seven drugs at admission and discharge $(6,8)$.

Antithrombotic agents were the most prescribed drugs both at admission and at discharge, followed by drugs for peptic ulcer and gastroesophageal reflux disease (GERD), high ceiling diuretics and ACE-inhibitors. Drugs for peptic ulcer and GERD showed the largest increase at discharge, shifting from $41 \%$ at admission to $56 \%$. This might indicate an area of inappropriate prescribing that was specifically assessed in an ad-hoc analysis (36), where more than $60 \%$ of patients receiving these drugs had no specific indication to their use.

Predictors of polypharmacy in hospital in-patients has been examined only in a few studies (6-7), which indicated different sociodemographic and clinical factors, such as age, sex, living alone, multiple pathologies, and some specific chronic diseases (e.g. hypertension, diabetes mellitus, heart failure, CVD, and COPD). We too found that age, number of drugs at admission, hypertension, ischemic heart disease, heart failure, and COPD were predictors of polypharmacy at discharge. 
As in other studies (6-8), the present results indicate that several cardiovascular chronic diseases at admission should be considered a predictor of polypharmacy at discharge, because the worsening of these chronic disorders might justify the prescription of new drugs over and above previous home therapy. Furthermore, clinicians might add new drug therapies at discharge to manage the conditions that led to the hospital admission, or to "prevent" some disease or drug-related risk, such as gastroprotective agents for patients taking aspirin or non-steroidal anti-inflammatory drugs, or polypharmacy itself.

Another reason for polypharmacy is often the need to treat some chronic condition such as diabetes, hypertension, heart failure and atrial fibrillation, according to the guidelines for each disease. In many cases guidelines for each specific disease support the need to prescribe more than one drug, but only in a few cases they take into account the patient's comordities and the number and type of drugs currently taken $(10,21,27-29,37)$.

Although the absolute number of drugs cannot be considered a direct indicator of prescribing appropriateness, there is growing evidence that polypharmacy is associated with increases in many adverse outcomes, including adverse drug reactions, drug-drug or drug-disease interactions, falls, hospital admission, and mortality (3-4,16,20,29). Moreover, although analysis of the appropriateness of drug prescribing was not the aim of our paper, we do want stress the importance of reviewing drug regimens for older persons in hospital taking multiple medications, as discussed in the ACOVE quality indicators for appropriate drug use in vulnerable elders (39). However, considering the small proportion of enrolled patients whose medications at discharge were fewer than at admission, our study seems to suggest that hospitalization fails as an important step for reviewing patient's drug regimens, and that clinicians still prefer a disease-oriented approach (2829). 


\section{Length of hospital stay and in-hospital mortality}

One study found that the number of drugs used at hospital admission was related to the number of drug-related problems while in hospital. The risk of a drug-related problem increased with each additional drug supplied in hospital; this linear relationship was present over the whole range of drugs, without any specific number (9).

To our knowledge, only one report has analyzed the relation between polypharmacy and the length of hospital stay and in-hospital mortality (8). This study too found that polypharmacy was not related to the length of hospital stay or in-hospital mortality. We also found, as expected, that the occurrence of AEs in hospital was the most significant predictor for these outcomes, prolonging the hospital stay by nearly four days, and raising the risk of in-hospital death seven-fold. Only a case of suspected adverse drug reaction was reported by clinicians. This low rate is probably due to the lack of an explicit request to signal ADR and to the well known under-reporting of suspected ADR by physicians.

Although common consequences of polypharmacy include ADRs that can negatively influence outcomes, probably an account of the restricted window of observation during the hospital stay or to the "diluted effect" of the number of prescribed drugs, we could not find any effects of polypharmacy on the major clinical outcomes. Furthermore, polypharmacy may be unavoidable and appropriate in some patients, especially when it is carefully prescribed and monitored.

\section{Strengths and limitations}

The major strengths of the REPOSI study include the multicenter design that involved 38 internal medicine and geriatric wards throughout Italy, resulting in a sample representative of the hospitalized elderly population; second, patients were enrolled in four different weeks (one per season) in order to balance the effect of seasons on the acute diseases leading to hospital admission. 
However, a few limitations must also be mentioned. First, problems can arise when using hospital data for research, because hospital records are not designed for this purpose but rather for patient care, and their diagnostic quality may vary depending on different hospitals, physicians and clinical units, they also do not routinely collect data on disability and cognitive status. Moreover, admissions are often selective on the basis of local characteristics, associated medical conditions and admissions policies, which can vary from hospital to hospital. Second, the REPOSI data set was not planned to include multidimensional geriatric assessment, because it is not a general practice in internal medicine wards. Thus we have no information on patient's functional profiles. Third, the study did not allow any general conclusion about the number of drugs taken before admission, or on the appropriateness of drugs prescribed. We did not include over-the-counter drugs or herbal medicines taken before admission.

\section{Conclusions}

Although the published studies on polypharmacy did not all use the same cut-off point, undoubtedly elderly in-patients are exposed to a large number of drugs, often on a chronic basis, and hospitalization often leads to a significant increase in the number of medications. When assessing the risk of polypharmacy, clinicians should carefully consider the patient's age, the number and type of drugs at admission, and the presence of any chronic disease such as hypertension, ischemic heart disease, heart failure, or COPD. At discharge the presence of polypharmacy and an increase in the number of drugs should alert clinicians to carefully review each patient's drug portfolio with the aim of withdrawing useless or inappropriate medications. Last but not least, the occurrence of an $\mathrm{AE}$ in hospital should raise the level of clinical monitoring for the patient, because AEs are strongly related to the risk of prolonging the hospital stay or in-hospital mortality. 


\section{Acknowledgments}

We are grateful to Judith Baggott for editorial assistance.

Financial Disclosure: Carlotta Franchi holds a fellowship granted by Rotary Clubs Milano Naviglio Grande San Carlo, Milano Scala and Inner Wheel Milano San Carlo.

Conflict of interest: All the authors declare that no conflict of interest exist. All the authors state that they have a full control of data and that they agree to allow the journal to review their data if requested.

\section{Authors' contribution:}

Study concept and design: Corrao, Licata, Mannucci, Nobili, Salerno, Tettamanti. Data acquisition: All authors and SIMI investigators. Data analysis and interpretation: Corrao, Franchi, De Vittorio, Iorio, Licata, Mannucci, Marcucci, Marengoni, Nobili, Pasina, Salerno, Tettamanti. Drafting the manuscript: Nobili, Salerno, Tettamanti. Critical review of the manuscript: Corrao, Franchi, De Vittorio, Iorio, Licata, Mannucci, Marcucci, Marengoni, Nobili, Pasina, Salerno, Tettamanti.

Sponsor Role: The REPOSI study is a network of Italian internal medicine hospital wards which on a voluntary basis, and without any economic support, agreed to participate in data collection during four index weeks.

Funding sources: Nothing. 


\section{APPENDIX: REPOSI COLLABORATORS AND PARTICIPATING UNITS}

The following hospital and investigators have contributed to this study: Pier Mannuccio Mannucci, Alberto Tedeschi, Raffaella Rossio (Medicina Interna 2, Fondazione IRCCS Ospedale Maggiore, Milano); Guido Moreo, Barbara Ferrari (Medicina Interna 3, Fondazione IRCCS Ospedale Maggiore, Milano); Cesare Masala, Antonio Mammarella, Valeria Raparelli (Medicina Interna, Università La Sapienza, Roma); Carulli Nicola, Stefania Rondinella, Iolanda Giannico (Medicina Metabolica, Università di Modena e Reggio Emilia); Leonardo Rasciti, Silvia Gualandi (Medicina Interna, Policlinico S. Orsola Malpighi, Bologna); Valter Monzani, Valeria Savojardo (Medicina d'Urgenza, IRCCS Fondazione Ospedale Maggiore, Milano); Cappellini Maria Domenica, Giovanna Fabio, Flavio Cantoni (Medicina Interna 1A, Fondazione IRCCS Ospedale Maggiore, Milano); Dallegri Franco, Luciano Ottonello, Alessandra Quercioli, Alessandra Barreca (Medicina Interna 1, Università di Genova); Riccardo Utili, Emanuele Durante-Mangoni, Daniela Pinto (Medicina Interna, Seconda Università di Napoli); Roberto Manfredini, Elena Incasa, Emanuela Rizzioli (Medicina Interna, Azienda USL, Ferrara); Massimo Vanoli, Gianluca Casella (Medicina Interna, Ospedale di Lecco, Merate); Giuseppe Musca, Olga Cuccurullo (Medicina Interna, P.O. Cetraro, ASP Cosenza); Laura Gasbarrone, Giuseppe Famularo, Maria Rosaria Sajeva (Medicina Interna, Ospedale San Camillo Forlanini, Roma); Antonio Picardi, Dritan Hila (Medicina ClinicaEpatologia, Università Campus Bio-Medico, Roma); Renzo Rozzini, Alessandro Giordano (Fondazione Poliambulanza, Brescia); Andrea Sacco, Antonio Bonelli, Gaetano Dentamaro (Medicina, Ospedale Madonna delle Grazie, Matera); Francesco Salerno, Valentina Monti, Massimo Cazzaniga (Medicina Interna, IRCCS Policlinico San Donato, Università di Milano); Ingrid Nielsen, Piergiorgio Gaudenzi, Lisa Giusto (Medicina ad Alta Rotazione, Azienda Ospedaliera Universitaria, Ferrara); Enrico Agabiti Rosei, Damiano Rizzoni, Luana Castoldi (Clinica Medica, Università di Brescia); Daniela Mari, Giuliana Micale (Medicina Generale ad indirizzo Geriatrico, IRCCS Istituto Auxologico Italiano, Milano); Emanuele Altomare, Gaetano Serviddio, Santina Salvatore (Medicina Interna, Università di Foggia); Carlo Longhini, Cristian Molino (Clinica Medica, Azienda Mista Ospedaliera Universitaria Sant'Anna, Ferrara); Giuseppe Delitalia, Silvia Deidda, Luciana Maria Cuccuru (Clinica Medica, Azienda Mista Ospedaliera Universitaria, Sassari); Giampiero Benetti, Michela Quagliolo, Giuseppe Riccardo Centenaro (Medicina 1, Ospedale di Melegnano, Vizzolo Predabissi, Milano); Alberto Auteri, Anna Laura Pasqui, Luca Puccetti (Medicina Interna, Azienda Ospedaliera Universitaria Le Scotte, Siena); 
Carlo Balduini, Giampiera Bertolino, Piergiorgio Cavallo (Dipartimento di Medicina Interna, Fondazione IRCCS Policlinico San Matteo, Università degli Studi di Pavia); Ronchi Esio, Daniele Bertolini, Nicola Lucio Liberato (Medicina Interna, Ospedale Carlo Mira, Casorate Primo, Pavia); Antonio Perciccante, Alessia Coralli (Medicina, Ospedale San Giovanni-Decollato-Andisilla, Civita Castellana); Luigi Anastasio, Leonardo Bertucci (Medicina Generale, Ospedale Civile Serra San Bruno); Giancarlo Agnelli, Ana Macura, Alfonso Iorio, Maura Marcucci (Medicina Interna e Cardiovascolare, Ospedale Santa Maria della Misericordia, Università di Perugia); Cosimo Morabito, Roberto Fava (Medicina, Ospedale Scillesi d'America, Scilla); Giuseppe Licata, Antonino Tuttolomondo, Riccardo Di Sciacca (Medicina Interna e Cardioangiologia, Università degli Studi di Palermo); Luisa Macchini, Anna Realdi (Clinica Medica 4, Università di Padova); Luigi Cricco, Alessandra Fiorentini, Cristina Tofi (Geriatria, Ospedale di Montefiascone); Carlo Cagnoni, Antonio Manucra (UO Medicina e Primo Soccorso, Ospedale di Bobbio, Azienda USL di Piacenza); Giuseppe Romanelli, Alessandra Marengoni, Bonometti Francesca (UO Geriatria, Spedali Civili di Brescia); Michele Cortellaro, Maria Rachele Meroni, Magenta Marina (Medicina 3, Ospedale Luigi Sacco, Università di Milano); Carlo Vergani, Dionigi Paolo Rossi (Geriatria, Fondazione IRCCS Ospedale Maggiore e Università di Milano).

Clincal data monitoring and revision: Valentina Spirito, Damia Noce, Jacopo Bonazzi, Rossana Lombardo, Luigi de Vittorio (Istituto di Ricerche Farmacologiche “Mario Negri”, Milano). 


\section{References}

1. Gurwitz JH. Polypharmacy. A new paradigm for quality drug therapy in the elderly? Arch Intern Med 2004; 164: 1957-59.

2. Hajjar ER, Cafiero AC, Hanlon JT. Polypharmacy in elderly patients. Am J Geriatr Pharmacother 2007; 5: 345-51.

3. Hilmer SN \& Gnjidic D. The effects of polypharmacy in older adults. Clin Pharmacol Therapeutics 2009; 85: 86-98.

4. Steinman MA, Landefeld CS, Rosenthal GE, et al. Polypharmacy and prescribing quality in older people. J Am Geriatr Soc 2006;54: 1516-1523.

5. Kaufman DW, Kelly JP, Rosemberg L, Anderson TE, Mitchell AA. Recent patterns of medication use in the ambulatory adult population of the united State: the Slone survey. JAMA 2002; 287: 337-44.

6. Corsonello A, Pedone C, Corica F, Antonelli Incalzi R, on behalf of the Gruppo Italiano di Farmacovigilanza (GIFA) investigators. Polypharmacy in the elderly patients at discharge from the acute care hospital. Therapeutics and Clinical Risk Management 2007; 3: 197-203.

7. Wawruch M, Zikavska M, Wsolova L, Kuzelova M, Tisonova J, Gajdosik J, et al. Polyphramacy in elderly hospitalised patients in Slovakia. Pharm World Sci 2008; 30: 235-42.

8. Schuler J, Duckelmann C, Beindl W, Prinz E, Michalski T, Pichelr M. Polypharmacy and inappropriate prescribing in elderly internal medicine patients in Austria. Wien Klin. Wochenschr 2008; 120: 733-41.

9. Viktil KK, Blix HS, Moger TA, Reikvam A. Polypharmacy as commonly defined is an indicator of limited value in the assessment of drug-related problems. Br J Clin Pharmacol 2006; 63: 187-195.

10. Milton JC, Hill-Smith I, Jackson SHD. Prescribing for older people. BMJ 2008; 336: 606-9.

11. Simonson W, Feinberg JL. Medication-related problems in the elderly. Defining the issues and identifying solutions. Drug Aging 2005; 22: 559-69.

12. Veehof LJG, Stewart RE, Haaijer-Raskamp FM, Meyboom-de Jong B. The development of polypharmacy. A longitudinal study. Fam Pract 2000; 17: 261-67.

13. Linjakumpu T, Hartkainen S, Klaukka T, Veijola J. Kivela SL, Isoaho R. Use of medications and polypharmacy are increasing among elderly. J Clin Epidemiol 2002; 55: 809-17.

14. Koh Y, Kutty FBM, Li SC. Drug-related problems in hospitalized patients on polypharmacy: the influence of age and gender. Therapeutics and Clinical Risk Management 2005; 1: 39-48.

15. Lund BC, Camahan RM, Egge JA, Chrischilles EA, Kaboli PJ. Inappropriate prescribing predicts adverse drug events in older adults. Ann Pharmacother 2010; DOI 10.1345/aph.1M657.

16. Spinewine A, Schmader KE, Barber N, et al. Appropriate prescribing in elderly people: how well can it be measured and optimised?. Lancet 2007; 370: 173-84.

17. Veehof LJG, Meyboom-de Jong B, Haaijer-Raskamp FM. Polypharmacy in the elderly-a literature review. Eur J Gen Pract 2000; 6: 98-106.

18. Jyrkka J, Enlund H, Korhonen MJ, Sulkava R, Hartikainen S. Polypharmacy stauts as an indicator of mortality in an elderly population. Drugs Aging 2009; 26: 1039-48. 
19. Onder G, Pedone C, Landi F, Cesari M, Vedova C, Bernabei R, et al. Adverse drug reactions as cause of hospital admission: results from the Italian Group of Pharmacoepidemiology in the Elderly (GIFA). J Am Geriatr Soc 2002; 50: 1962-68.

20. Onder G, Landi F, Liperoti R, Fialova D, Gambassi G, Bernabei R. Impact of inappropriate drug use among hospitalized older adults. Eur J Clin Pharmacol 2005; 61: 1453-59.

21. Bressler R, Bahl JJ. Principles of drug therapy for the elderly patients. Mayo Clin Proc 2003; 78: 156477.

22. van den Akker M, Buntinx F, Knottnerus JA. Comorbidity or multimorbidity: what's in a name? A review of literature. Eur J Gen Pract. 1996;2:65-70.

23. van den Akker M, Buntinx F, Metsemakers JF, et al. Multimorbidity in general practice: prevalence, incidence, and determinants of co-occurring chronic and recurrent diseases. J Clin Epidemiol. 1998;51:367-375

24. Verbrugge LM, Lepkowski JM, Imanaka Y. Comorbidity and its impact on disability. Milbank Q 1989;67:450-484

25. Gijsen R, Hoeymans N, Schellevis FG, Ruwaard D, Satariano WA, van den Bos GA. Causes and consequences of comorbidity: a review. J Clin Epidemiol. 2001;54:661-674.

26. Wolff JL, Starfield B, Anderson G.. Prevalence, expenditures, and complications of multiple chronic conditions in the elderly. Arch Intern Med 2002; 162:2269-2276.

27. Boyd CM, Ritchie CS, Tipton EF, Studenski SA, Wieland D. From bedside to bench: summary from the American Geriatrics Society/National Institute on Aging Research conference on comorbidity and multiple morbidity in older adults. Aging Clin Exp Res 2008;20:181-188.

28. Tinetti ME, Bogardus ST, Agostini JV. Potential pitfalls of disease-specific guidelines for patients with multiple conditions. N Engl J Med 2004; 351: 2870-74.

29. Boyd CM, Darer J, Boult C, et al. Clinical practice guidelines and quality of care for older patients with multiple comorbid diseases: implications for pay for performance. JAMA 2005;294:716

30. Creditor MC. Hazard of hospitalization of the elderly. Ann Intern Med 1993; 118: 219-223.

31. World Health Organization. (1987). International Classification of Diseases, Injuries, and Causes of Death. Ninth Revision (ICD-9). Geneva: World Health Organization. http://icd9cm.chrisendres.com/ accessed July 12, 2010.

32. Charlson ME, Pompei P, Ales KL, MacKenzie CR. A new method of classifying prognostic comorbidity in longitudinal studies: development and validation. J Chronic Dis 1987;40:373-383

33. World Health Organization. Guidelines for ATC Classification. Sweden, WHO Collaborating Centre for Drug Statistics Methodology, Norway and Nordic Councils on Medicines, 1990.

34. Bernardini B, Meinecke C, Zaccarini C, Bongiorni N, Fabbrini S, Gilardi C, Bonaccorso O, Guaita A. Adverse clinical events in dependent long-term nursing home residents. J Am Geriatr soc 1993; 41: 105-111.

35. Bellelli G, Frisoni GB, Barbisoni P, Beffelli S, Rozzini R, Trabucchi M. The management of adverse clinical events in nursing homes: a 1-years survey study. J Am Geriatr soc 2001; 49: 915-925. 
36. Pasina L, Nobili A, Tettamanti M, Salerno F, Corrao S, Bonazzi J, Vicidomini R, Mannucci PM, a nome del partecipanti al Progetto Registro Politerapie SIMI. Utilizzo e appropriatezza d'uso dei farmaci anti-ulcera peptica/reflusso gastroesofageo in una coorte di anziani ricoverati in reparti di medicina interna. Intern Emerg Med 2009; 4: S69.

37. Redelmeier DA, Tan SH, Booth GL. 1998. The treatment of unrelated disorders in patients with chronic medical diseases. N Eng J Med 338:1516-1520.

38. Holmes HM. Rational prescribing for patients with a reduced life expectancy. Clin Pharmacol Therapeutics 2009; 85: 103-7.

39. Knight EL, Avorn J. Quality indicators for appropriate medication use in vulnerable elders. An Intern Med 2001; 135: 703-710. 
Table 1. Ten most frequently prescribed drug classes (3rd level of ATC classification).

\begin{tabular}{|l|c|c|}
\hline & $\begin{array}{c}\text { At admission } \\
(132 \text { patients }) \\
\text { No. }(\%)\end{array}$ & $\begin{array}{c}\text { At discharge } \\
(1155 \text { patients }) \\
\text { No. }(\%)\end{array}$ \\
\hline B01A, antithrombotic agents & $692(52.0)$ & $690(59.7)$ \\
\hline A02B, drugs for peptic ulcer and GERD & $546(41.0)$ & $647(56.0)$ \\
\hline C03C, high ceiling diuretics & $465(34.9)$ & $454(39.3)$ \\
\hline C09A, ACE inhibitors & $359(27.0)$ & $361(31.3)$ \\
\hline C07A, beta-blocking agents & $334(25.1)$ & $329(28.5)$ \\
\hline C10A, lipid modifying agents & $230(17.3)$ & $210(18.2)$ \\
\hline A10B, blood glucose lowering drugs, excl. insulins & $205(15.4)$ & $168(14.6)$ \\
\hline C01A, cardiac glycosides & $119(8.9)$ & $105(9.1)$ \\
\hline C01D, vasodilators used in cardiac diseases & $224(16.8)$ & $223(19.3)$ \\
\hline A10A, insulins and analogues & $111(8.3)$ & $129(11.2)$ \\
\hline
\end{tabular}

ATC, Anatomical Therapeutic Chemical classification; GERD, gastro-esophageal reflux disease; ACE, angiotensin-converting enzyme 
Table 2. Univariate analysis of predictors of polypharmacy (five or more drugs) at admission and discharge.

\begin{tabular}{|c|c|c|c|c|c|c|}
\hline \multirow{2}{*}{ Variables } & \multicolumn{3}{|c|}{ Admission (1332) } & \multicolumn{3}{|c|}{ Discharge (1155) } \\
\hline & $\begin{array}{c}\text { No Polypharmacy } \\
(641)\end{array}$ & $\begin{array}{c}\text { Polypharmacy } \\
(691)\end{array}$ & $P$ & $\begin{array}{c}\text { No Polypharmacy } \\
(381)\end{array}$ & $\begin{array}{c}\text { Polypharmacy } \\
\text { (774) }\end{array}$ & $P$ \\
\hline \multicolumn{7}{|l|}{ Socio-demographic variables } \\
\hline Females, No. $(\%)$ & $359(56.0)$ & $363(52.5)$ & 0.20 & $206(54.1)$ & $414(53.5)$ & 0.85 \\
\hline Age (years), mean $( \pm \mathrm{SD})$ & $79.6(8.0)$ & $79.2(7.2)$ & 0.35 & $79.8(8.2)$ & $78.9(7.2)$ & 0.08 \\
\hline Age $\geq 75$ years, No. $(\%)$ & $446(69.6)$ & $482(69.8)$ & 0.94 & $268(70.3)$ & $533(68.9)$ & 0.61 \\
\hline Age $\geq 85$ years, No. $(\%)$ & $178(27.8)$ & $146(21.1)$ & 0.004 & 109 (28.6) & $160(20.7)$ & 0.003 \\
\hline Education (years), mean $( \pm \mathrm{SD})$ & $6.1(3.5)$ & $6.54(3.8)$ & 0.03 & $5.9(3.7)$ & 6. $6(3.8)$ & 0.006 \\
\hline Widow/er, No. (\%) & $265(41.3)$ & $282(40.8)$ & 0.89 & $161(42.2)$ & $310(40.1)$ & 0.54 \\
\hline Living alone, No. (\%) & $152(23.7)$ & $163(23.6)$ & 0.95 & $102(26.8)$ & $176(22.7)$ & 0.15 \\
\hline \multicolumn{7}{|l|}{ Clinical variables } \\
\hline Number of diagnoses, mean $( \pm \mathrm{SD})$ & $3.3(2.0)$ & $5.1(2.3)$ & $<0.0001$ & $5.0(2.1)$ & $6.8(2.4)$ & $<0.0001$ \\
\hline Five or more diagnoses, No. (\%) & $273(42.6)$ & $527(76.3)$ & $<0.0001$ & $126(33.1)$ & $556(71.8)$ & $<0.0001$ \\
\hline Charlson index, mean score $( \pm \mathrm{SD})$ & $2.0(2.6)$ & $3.0(2.5)$ & $<0.0001$ & $2.2(2.3)$ & $3.3(2.9)$ & $<0.0001$ \\
\hline Charlson index score $\leq 2$, No. $(\%)$ & $455(71.0)$ & $322(48.1)$ & \multirow{3}{*}{$<0.0001$} & $255(67.3)$ & $330(42.6)$ & \multirow{3}{*}{$<0.0001$} \\
\hline Charlson index score $=3-4$, No. $(\%)$ & $125(19.5)$ & $220(31.8)$ & & $85(22.4)$ & $271(35.1)$ & \\
\hline Charlson index score $\geq 5$, No. $(\%)$ & $61(9.5)$ & $139(20.1)$ & & $39(10.3)$ & $173(22.3)$ & \\
\hline Number of drugs, mean $( \pm$ SD) & $2.6(1.2)$ & $7.1(2.1)$ & $<0.0001$ & $4.2(1.9)$ & $7.7(2.6)$ & $<0.0001$ \\
\hline Five or more drugs, No. (\%) & $==$ & $691(51.9)$ & $==$ & $==$ & $774(67.0)$ & $==$ \\
\hline AEs, mean $( \pm \mathrm{SD})$ & $0.6(1.1)$ & $0.7(1.2)$ & 0.083 & $0.5(1.0)$ & $0.6(1.1)$ & 0.02 \\
\hline One AE, No. (\%) & $137(21.4)$ & $160(23.2)$ & \multirow{2}{*}{0.06} & $80(21.0)$ & $160(20.7)$ & \multirow{2}{*}{0.01} \\
\hline More than one AEs, No. (\%) & $78(12.2)$ & $110(15.9)$ & & $32(8.4)$ & $112(14.5)$ & \\
\hline Hospital stay - days, mean $( \pm \mathrm{SD})$ & $11.0(9.3)$ & $11.0(7.9)$ & 0.97 & $10.2(8.6)$ & $10.9(7.7)$ & 0.15 \\
\hline \multicolumn{7}{|l|}{ Comorbid diseases, No. (\%) } \\
\hline Hypertension & $334(52.1)$ & $441(63.8)$ & $<0.0001$ & $192(50.4)$ & $509(65.76)$ & $<.0001$ \\
\hline Ischemic heart disease & $72(11.2)$ & $242(35.0)$ & $<0.0001$ & $37(9.7)$ & $259(33.46)$ & $<.0001$ \\
\hline Atrial fibrillation & $92(14.4)$ & 165 (23.9) & 0.0001 & $54(14.2)$ & $198(25.58)$ & $<.0001$ \\
\hline Heart failure & $63(9.8)$ & $129(18.7)$ & $<0.0001$ & $21(5.5)$ & $194(25.06)$ & $<.0001$ \\
\hline Diabetes mellitus & $86(13.4)$ & $244(35.3)$ & $<0.0001$ & $55(14.4)$ & $257(33.20)$ & $<.0001$ \\
\hline COPD/bronchial asthma & $98(15.3)$ & $174(25.2)$ & $<0.0001$ & $53(13.9)$ & $198(25.58)$ & $<.0001$ \\
\hline Dementia & $45(7.0)$ & $59(8.5)$ & 0.30 & $41(10.8)$ & $65(8.40)$ & 0.18 \\
\hline
\end{tabular}




\begin{tabular}{|c|c|c|c|c|c|c|}
\hline Cerebrovascular disease & $133(20.8)$ & $172(24.9)$ & 0.07 & $92(24.2)$ & $216(27.91)$ & 0.19 \\
\hline Depression & $3(0.5)$ & $7(1.0)$ & 0.25 & $1(0.3)$ & $3(0.39)$ & 0.74 \\
\hline Liver disease & $50(7.8)$ & $72(10.4)$ & 0.10 & $43(11.3)$ & $93(12.02)$ & 0.74 \\
\hline GI disorders & $84(13.1)$ & $132(19.1)$ & 0.003 & $60(15.8)$ & $151(19.5)$ & 0.13 \\
\hline Osteoporosis/osteoarthritis & $96(15.0)$ & $109(15.8)$ & 0.69 & $43(11.3)$ & $132(17.1)$ & 0.01 \\
\hline Chronic renal failure & $47(7.3)$ & $153(22.1)$ & $<0.0001$ & $27(7.1)$ & $163(21.1)$ & $<0.0001$ \\
\hline Anemia & $88(13.7)$ & $102(14.8)$ & 0.59 & $67(17.6)$ & $165(21.3)$ & 0.15 \\
\hline Malignancy & $114(17.8)$ & $132(19.1)$ & 0.54 & $100(26.3)$ & $184(23.8)$ & 0.33 \\
\hline
\end{tabular}

AE, Adverse clinical event; COPD, Chronic obstructive pulmonary disease; GI, gastrointestinal. 
Table 3. Univariate analysis of predictors of polypharmacy (five or more drugs) at discharge for 551 patient admitted without polypharmacy.

\begin{tabular}{|c|c|c|c|}
\hline Variables* & $\begin{array}{c}\text { No polypharmacy } \\
341(61.9 \%)\end{array}$ & $\begin{array}{c}\text { Polypharmacy } \\
210(38.1 \%)\end{array}$ & $P$ \\
\hline \multicolumn{4}{|l|}{ Socio-demographic variables } \\
\hline Females, No. (\%) & $182(53.4)$ & $120(57.1)$ & 0.39 \\
\hline Age (years), mean $( \pm \mathrm{SD})$ & $79.6(8.2)$ & $79.1(7.5)$ & 0.49 \\
\hline Age $\geq 75$ years, No. $(\%)$ & $237(69.5)$ & $144(68.6)$ & 0.82 \\
\hline Age $\geq 85$ years, No. $(\%)$ & $95(27.9)$ & $51(24.3)$ & 0.36 \\
\hline Education (years), mean $( \pm \mathrm{SD})$ & $5.9(3.6)$ & $6.5(3.6)$ & 0.09 \\
\hline Widow/er, No. (\%) & $140(41.1)$ & $79(38.0)$ & 0.48 \\
\hline Living alone, No. (\%) & $87(25.7)$ & $43(20.7)$ & 0.18 \\
\hline \multicolumn{4}{|l|}{ Clinical variables } \\
\hline Number of diagnoses, mean $( \pm \mathrm{tSD})$ & $3.8(1.8)$ & $5.0(1.9)$ & $<0.0001$ \\
\hline Five or more diagnoses, No. (\%) & $101(29.6)$ & $121(57.6)$ & $<0.0001$ \\
\hline Charlson index, mean score $( \pm \mathrm{(SD})$ & $1.7(2.2)$ & $2.1(2.6)$ & 0.04 \\
\hline Charlson index score $\leq 2$, No. $(\%)$ & $256(75.1)$ & $144(68.6)$ & \multirow{3}{*}{0.24} \\
\hline Charlson index score $=3-4$, No. $(\%)$ & $59(17.3)$ & $47(22.4)$ & \\
\hline Charlson index score $\geq 5$, No. $(\%)$ & $26(7.6)$ & $19(9.1)$ & \\
\hline Number of drugs, mean $( \pm$ SD $)$ & $2.2(1.2)$ & $3.2(1.0)$ & $<0.0001$ \\
\hline AEs, mean $( \pm$ SD $)$ & $0.4(0.9)$ & $0.6(1.2)$ & 0.04 \\
\hline One AE, No. (\%) & $71(20.8)$ & $35(16.7)$ & \multirow{2}{*}{0.01} \\
\hline More than one AE, No. (\%) & $25(7.3)$ & $32(15.2)$ & \\
\hline Hospital stay - days, mean $( \pm S D)$ & $9.9(8.7)$ & $11.5(8.1)$ & 0.03 \\
\hline \multicolumn{4}{|l|}{ Comorbid diseases, $\mathrm{N}(\%)$} \\
\hline Hypertension & $156(45.8)$ & $139(66.2)$ & $<0.0001$ \\
\hline Ischemic heart disease & $26(7.6)$ & $33(15.7)$ & 0.003 \\
\hline Atrial fibrillation & $35(10.3)$ & $38(18.1)$ & 0.009 \\
\hline Heart failure & $13(3.8)$ & $38(18.1)$ & $<0.0001$ \\
\hline Diabetes mellitus & 40 (11.7) & $32(15.2)$ & 0.24 \\
\hline
\end{tabular}




\begin{tabular}{|l|c|c|c|}
\hline COPD/bronchial asthma & $37(10.9)$ & $40(19.1)$ & 0.007 \\
\hline Dementia & $25(7.3)$ & $10(4.8)$ & 0.23 \\
\hline Cerebrovascular disease & $67(20.0)$ & $47(22.4)$ & 0.44 \\
\hline Depression & $1(0.3)$ & $2(1.0)$ & 0.31 \\
\hline Liver disease & $33(9.7)$ & $15(7.1)$ & 0.31 \\
\hline GI disorders & $46(13.5)$ & $25(11.9)$ & 0.59 \\
\hline Osteoporosis/osteoarthritis & $38(11.1)$ & $41(19.5)$ & 0.006 \\
\hline Chronic renal failure & $19(5.6)$ & $16(7.6)$ & 0.034 \\
\hline Anemia & $46(13.5)$ & $25(11.9)$ & 0.59 \\
\hline Malignancy & $63(18.5)$ & $29(13.8)$ & 0.15 \\
\hline
\end{tabular}

AE, Adverse clinical event; COPD, Chronic obstructive pulmonary disease; GI, gastrointestinal. 
Table 4. Multivariate analysis of predictors of polypharmacy at discharge among 1155 patients discharged to home.

\begin{tabular}{|l|c|c|}
\hline Variables & Odds ratio $†$ (95\% CI) & $\boldsymbol{P}$ \\
\hline Females & $1.00(0.75-1.32)$ & 0.98 \\
\hline Age (years), mean & $0.96(0.94-0.98)$ & $<0.0001$ \\
\hline Number of drugs at admission, mean & $2.32(1.96-2.74)$ & $<0.0001$ \\
\hline Adverse clinical events (one or more) & $1.08(0.72-1.63)$ & 0.70 \\
\hline Hypertension & $1.84(1.34-2.53)$ & $<0.0001$ \\
\hline Ischemic heart disease & $1.72(1.18-2.50)$ & 0.005 \\
\hline Heart failure & $3.77(1.77-8.01)$ & 0.001 \\
\hline Atrial fibrillation & $1.09(0.66-1.82)$ & 0.61 \\
\hline Diabetes mellitus & $0.88(0.54-1.43)$ & 0.70 \\
\hline COPD & $1.93(1.33-2.79)$ & 0.001 \\
\hline Dementia & $0.69(0.29-1.66)$ & 0.41 \\
\hline Cerebrovascular disease & $0.93(0.62-1.39)$ & 0.73 \\
\hline Liver disease & $0.90(0.49-1.63)$ & 0.72 \\
\hline GI disorders & $0.99(0.59-1.66)$ & 0.98 \\
\hline Osteoporosis/osteoarthritis & $1.44(0.84-2.46)$ & 0.18 \\
\hline Chronic renal failure & $0.98(0.51-1.89)$ & 0.96 \\
\hline Anemia & $0.88(0.56-1.40)$ & 0.59 \\
\hline Malignancy & $0.72(0.47-1.10)$ & 0.13 \\
\hline confince & \\
\hline
\end{tabular}

CI, confidence interval; COPD, Chronic obstructive pulmonary disease; GI, gastrointestinal.

$\uparrow$ Adjusted for sex (female $v s$. male), age (mean), number of drugs at admission (mean), occurrence of at least one $\mathrm{AE}$ in hospital, single diagnosis, and for the non-independence of patients within the same ward. 
Table 5. Outcome measures and predictors of outcome at discharge.

\begin{tabular}{|c|c|c|c|}
\hline & $\begin{array}{c}\text { No polypharmacy } \\
\text { (641 patients) } \\
\text { No. }(\%) \\
\end{array}$ & $\begin{array}{c}\text { Polypharmacy } \\
\text { (691 patients) } \\
\text { No. }(\%) \\
\end{array}$ & $P$ value \\
\hline \multicolumn{4}{|l|}{ Outcome measures } \\
\hline Hospital stay - days, mean ( $( \pm \mathrm{SD})$ & $11.0(9.3)$ & $11.0(7.9)$ & 0.97 \\
\hline Discharged. No. (\%) & $551(86.0)$ & $604(87.4)$ & \multirow{3}{*}{0.27} \\
\hline Transferred. No. (\%) & $61(9.5)$ & $50(7.2)$ & \\
\hline Died. No. $(\%)$ & $29(4.5)$ & $37(5.4)$ & \\
\hline \multicolumn{4}{|c|}{ Univariate and multivariate analysis } \\
\hline Length of hospital stay & $\begin{array}{l}\text { Regression coefficient } \\
(95 \% \text { CI })\end{array}$ & \multicolumn{2}{|c|}{$\begin{array}{c}\text { Regression coefficient } * \\
(95 \% \text { CI })\end{array}$} \\
\hline Females & $-0.14(-1.06 ; 0.79)$ & \multicolumn{2}{|c|}{$-0.19(-1.34 ; 0.96)$} \\
\hline Age (years) (mean) & $0.00(-0.06 ; 0.06)$ & \multicolumn{2}{|c|}{$-0.02(-0.11 ; 0.06)$} \\
\hline Charlson index, at admission (mean score) & $0.16(-0.03 ; 0.35)$ & \multicolumn{2}{|c|}{$0.09(-0.21 ; 0.39)$} \\
\hline Polypharmacy (five or more drugs) & $0.28(-0.64 ; 1.21)$ & \multicolumn{2}{|c|}{$-0.07(-1.30 ; 1.15)$} \\
\hline Adverse clinical events (one or more) & $3.56(2.60 ; 4.52) \#$ & \multicolumn{2}{|c|}{$3.57(2.32 ; 4.83) \#$} \\
\hline Mortality & Odds ratio $(95 \%$ CI $)$ & \multicolumn{2}{|c|}{ Odds ratio $*(95 \%$ CI $)$} \\
\hline Females & $0.97(0.59-1.60)$ & \multicolumn{2}{|c|}{$0.94(0.54-1.67)$} \\
\hline Age (years), mean & $1.05(1.02-1.09) \S$ & \multicolumn{2}{|c|}{$1.04(1.01-1.08) \dagger$} \\
\hline Charlson index, at admission (mean score) & $1.20(1.12-1.28) \#$ & \multicolumn{2}{|c|}{$1.18(1.12-1.24) \#$} \\
\hline Polypharmacy (five or more drugs) & $1.16(0.71-1.92)$ & \multicolumn{2}{|c|}{$1.00(0.59-1.69)$} \\
\hline Adverse clinical events (one or more) & 8.19 (4.41-15.2)\# & \multicolumn{2}{|c|}{6.80 (3.58-12.9)\# } \\
\hline
\end{tabular}

CI, confidence interval.

*Adjusted for sex (female vs. male), age (mean), comorbidity (Charlson index score, mean), number of drugs at admission (five or more), occurrence of at least one AE in hospital, and for the non-independence of patients within the same ward.

$\# \mathrm{p}<0.0001 ; \S \mathrm{p}=0.002 ; \dagger \mathrm{p}=0.02$. 
Figure 1. Prevalence of polypharmacy at admission in different age groups.

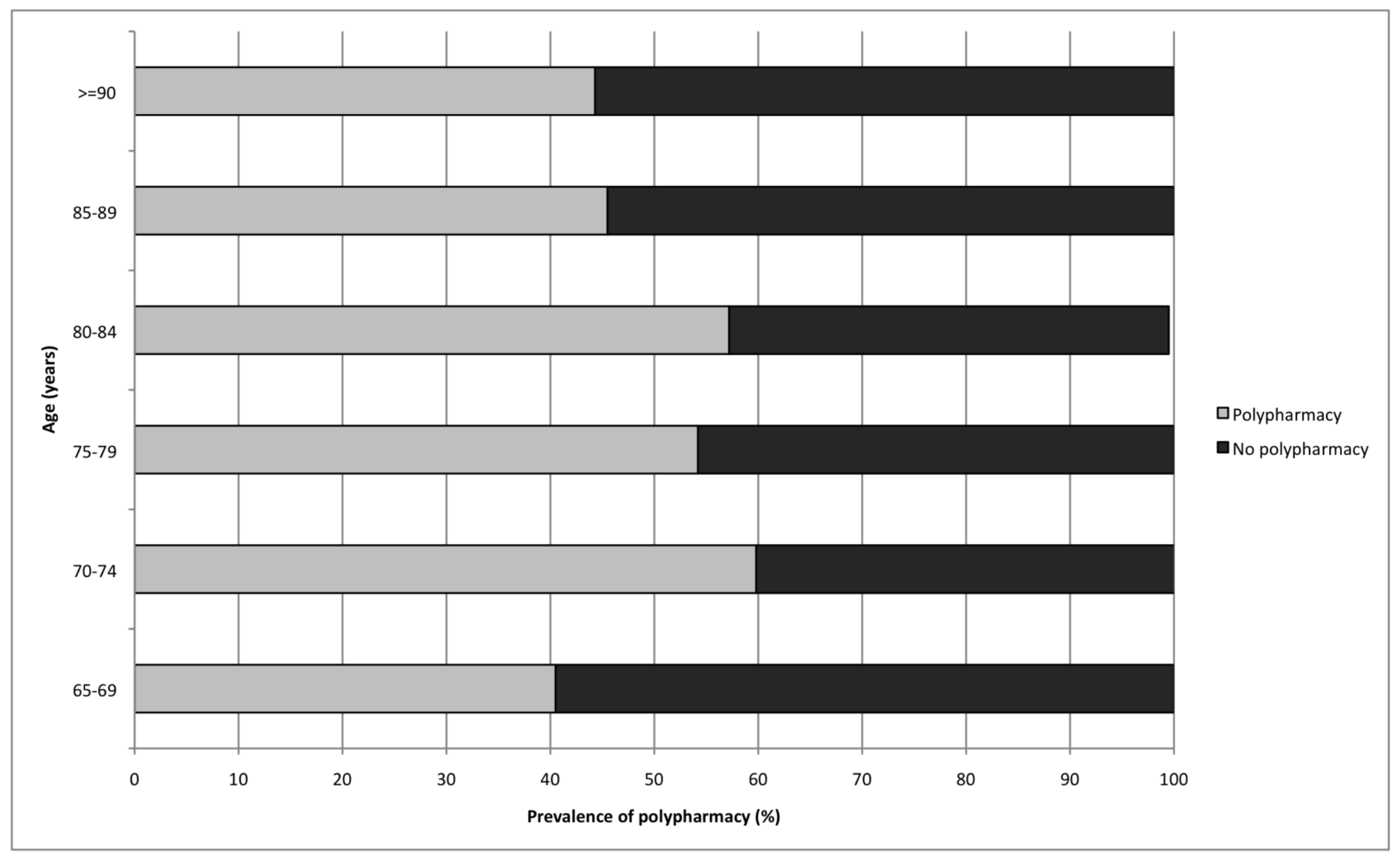


Figure 2. Prevalence of drug use at admission and at discharge in 1155 patients.

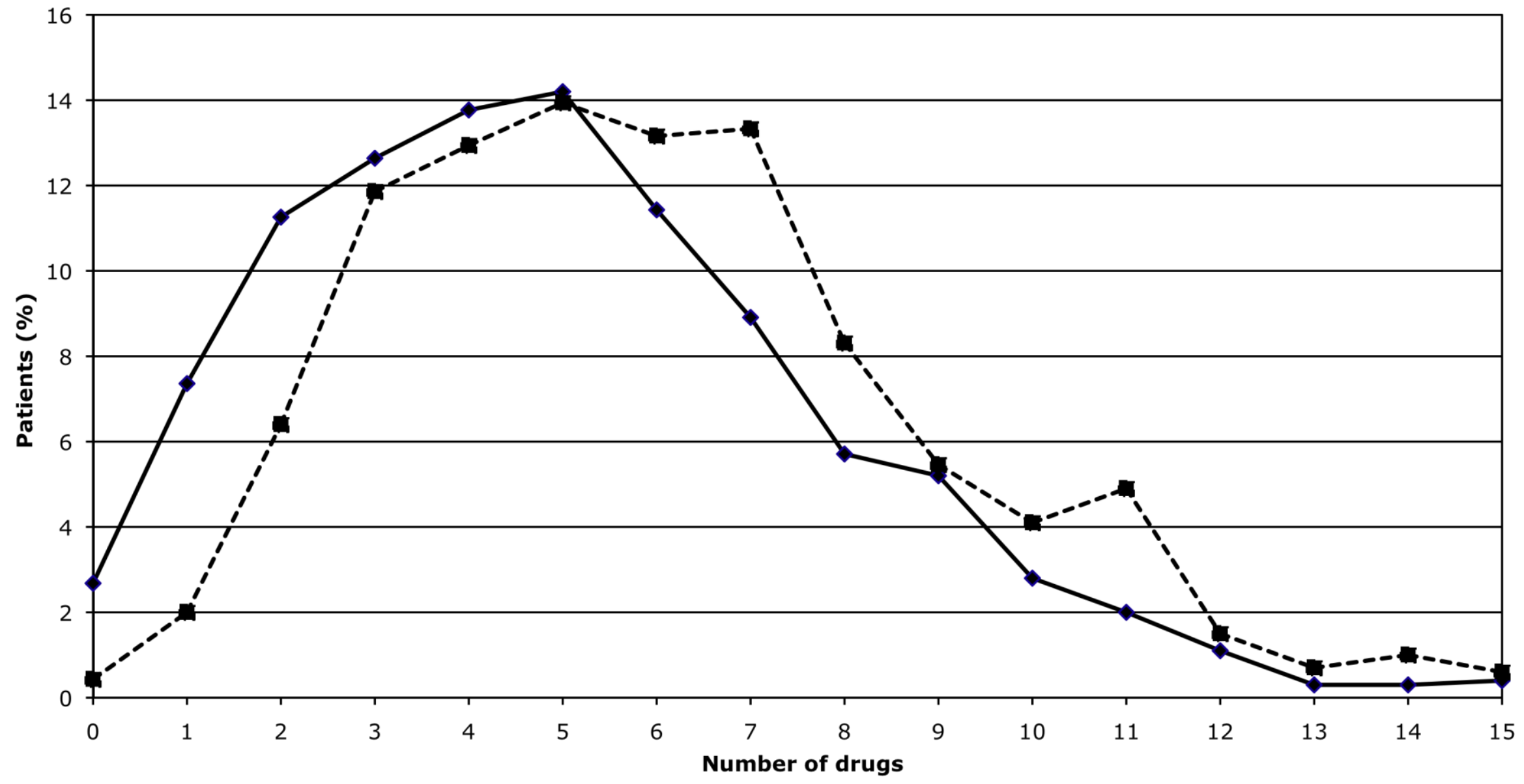

$\longrightarrow$ Admission - $\rightarrow-$ Discharge 